\title{
Preventing postoperative pneumonia: Spending a buck will save a buck
}

\author{
Harold L. Lazar, MD
}

\author{
From the Boston University School of Medicine, Boston, Mass. \\ Disclosures: Author has nothing to disclose with regard to commercial support. \\ Received for publication Jan 4, 2017; accepted for publication Jan 12, 2017; available ahead of print Feb 21, 2017. \\ Address for reprints: Harold L. Lazar, MD, Department of Cardiothoracic Surgery, Boston Medical Center, \\ 88 E Newton St, Suite B 404, Boston, MA 02118 (E-mail: Harold.1.lazar@ gmail.com). \\ J Thorac Cardiovasc Surg 2017;153:1392-3 \\ $0022-5223 / \$ 36.00$ \\ Copyright $(c) 2017$ by The American Association for Thoracic Surgery \\ http://dx.doi.org/10.1016/j.jtcvs.2017.01.014
}

In this edition of the Journal, Ailawadi and colleagues ${ }^{1}$ review the incidence, risk factors, and effects of postoperative pneumonia on mortality and health care costs in 5158 patients undergoing adult cardiac surgery in the Cardiothoracic Surgical Trials Network (CSTN). Although the incidence of postoperative pneumonia was only $2.4 \%$, it was associated with an 8.9-fold increase in mortality, a significant increase in hospital length of stay (23.5 days), and increased hospital costs by $\$ 38,000$.

A major limitation of this study is that it did not identify those patients with "isolated pneumonia" versus pneumonia associated with other perioperative complications such as strokes, acute renal failure, and sepsis. Therefore, we don't know how many patients actually died from pneumonia versus those patients who had life-threatening complications with pneumonia. The majority of risk factors in this study reflect the profiles of high-risk patients who currently undergo cardiac surgery. "Prolonged ventilation" and the use of nasogastric tubes were associated with an increased incidence of pneumonia; however, this may simply reflect the underlying severity of diseases found in these patients. It may be better to ventilate these patients longer until their secretions are minimal and their cardiac and mental status have returned to baseline, rather than attempting an "early extubation," which may require a subsequent "emergent" reintubation. Similarly, nasogastric tubes are necessary to prevent aspiration in obtunded patients and those with an ileus and to deliver antacids and important oral medications.

Despite these limitations, this study identified several new risk factors associated with postoperative pneumonia and exonerated several others. This information will allow for modification of patient management protocols to address the following areas outlined in the sections to follow.

\section{PERIOPERATIVE ANEMIA AND THE USE OF PERIOPERATIVE BLOOD PRODUCTS}

This study revealed that greater preoperative hemoglobin levels and platelet transfusions were protective for

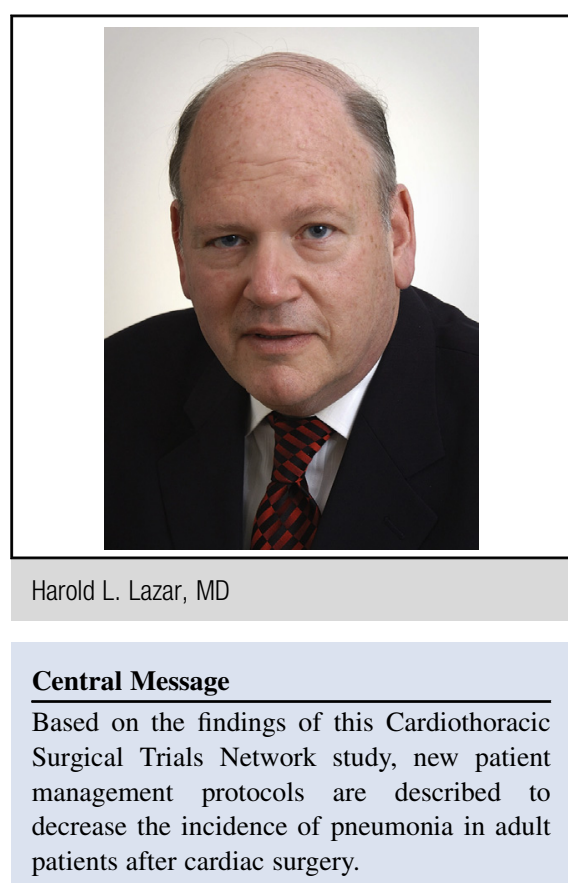

See Article page 1384. the development of pneumonia. Previous studies have shown that patients with preoperative hematocrit $<30 \%$ have an increased incidence of pulmonary infections ${ }^{2,3}$ and that perioperative platelet transfusions decrease postoperative morbidity and infections. ${ }^{4,5}$ Every effort should be made to correct anemia before surgery even if it means delaying the procedure and increasing preoperative length of stay. Diagnostic workups for occult blood loss and blood dyscrasia should be performed and a hematology consult obtained. Ironreplacement therapy should be instituted, and those patients with volume overload and pulmonary edema should undergo vigorous diuresis. Patients receiving clopidogrel and other antiplatelet agents should have their surgery postponed for 5 to 7 days if possible. ${ }^{6}$ During surgery, intraoperative coagulopathies should be corrected with blood component therapies and ultrafiltration and cellsaving techniques instituted, all of which have been associated with decreased red blood cell transfusions that increase pulmonary infections. ${ }^{7,8}$ Because postoperative anemia also has been associated with an increased incidence of pneumonia, patient management protocols should be designed to eliminate excessive blood draws, 
promote adequate diuresis, and recommend red blood cell transfusions for hemoglobin levels $<6 \mathrm{~g} / \mathrm{dL}^{6,9}$

\section{APPROPRIATE ANTIBIOTIC THERAPY}

The CSTN study noted that the most common bacteria associated with pneumonia were Pseudomonas aeruginosa, Klebsiella pneumonia, and Enterobacter cloacae. Current Society of Thoracic Surgeons guidelines advise the use of antibiotics that target staph species, the most common pathogens found in wound infections. Because none of these antibiotics cover Pseudomonas species, however, patients at high risk for pneumonia also should receive antibiotics with bactericidal properties against gram-negative organisms.

\section{ADMINISTRATION OF AGGRESSIVE PULMONARY TOILET THROUGHOUT THE POSTOPERARATIVE PERIOD}

In the CSTN trial, nearly one-half of patients who developed pneumonia did so during the first week after surgery. Most patients are extubated within 24 hours and leave the intensive care unit (ICU) by 48 hours; however, in many hospitals, the aggressive pulmonary toilet performed by skilled ICU-trained nurses is not available in non-ICU floors. This level of nursing care is essential for loosening secretions, performing proper airway suctioning, instituting and supervising incentive spirometry, and ensuring that patients are mobilized frequently and ambulated. In those hospitals when aggressive pulmonary toilet cannot be performed in non-ICU units, high-risk patients may need to spend longer periods in the ICU.

\section{POSTOPERATIVE MONITORING}

Another important observation of the CTSN study was that placement of femoral lines and the number of central lines were not predictive of postoperative pneumonia. Postoperative management protocols have advocated early removal of femoral and central lines to increase mobilization and prevent line sepsis. In these high-risk patients, however, maintaining these monitoring lines to optimize hemodynamics and monitor respiratory function ultimately may result in a decrease in pneumonia and respiratory insufficiency.

\section{TRANSFER TO APPROPRIATE REHABILITATION FACILITIES}

The CSTN study also provided important information on the timing of pneumonia. Pneumonia occurred in more than $30 \%$ of patients after the index hospitalization and in $14 \%$ of patients 30 days postsurgery. This implies that the level of pulmonary care required to prevent pneumonia is not maintained after hospital discharge. Patients at high risk for postoperative pneumonia should not be placed on fasttrack protocols and will require an extended period of hospital care to receive optimal pulmonary toilet. For those patients who require extended in-patient rehabilitation, they should be transferred to rehabilitation facilities with expertise in delivery of high-quality pulmonary care and pulmonary rehabilitation.

Decreasing the incidence of postoperative pneumonia in cardiac surgery will require that increased health care dollars be directed toward providing more skilled nursing personal, extended ICU and pre- and postoperative hospital stay, additional costs for antibiotics and blood products, and longer stays in specialized rehabilitation centers. Hospital and third-party payors may argue that these increased costs are not profitable for eliminating a complication with an incidence of only $2.4 \%$. A closer look at the numbers, however, would suggest that this complication significantly reduces profits for both hospitals and third-party payors.

This CSTN study is important in drawing our attention to this devastating complication and encourages the development and adoption of management protocols such as those developed for sternal wound infections, which have significantly decreased the incidence of this complication. ${ }^{10}$ Hospitals and third-party payors would be wise to support these practice management initiatives before the incidence of postoperative pneumonia in cardiac surgery is reported openly and penalties imposed on institutions with excessive rates. Perhaps then they will learn that to prevent postoperative pneumonia, "spending a buck will save a buck."

\section{References}

1. Ailawadi G, Chang HL, O'Gara PT, O'Sullivan K, Woo J, DeRose JJ, et al. Pneumonia after cardiac surgery: experience of the National Institutes of Health/Canadian Institutes of Health Research Cardiothoracic Surgical Trials Network. J Thorac Cardiovasc Surg. 2017;153:1384-91.e3.

2. Ranucci M, Conti D, Castelvecchio S, Menicanti L, Frigiola A, Ballott A, Pelissero G. Hematocrit on cardiopulmonary bypass and outcome after coronary surgery in non-transfused patients. Ann Thorac Surg. 2010;89:11-7.

3. Habib RH, Zacharias A, Schwann TA, Riordan CJ, Durham SJ, Shah A Adverse effects of low hematocrit during cardiopulmonary bypass in the adult: should current practice be changed? J Thorac Cardiovasc Surg. 2003;125: 1438-50.

4. McGrath T, Koch CG, Ku M, Li L, Mihaljenc T, Figueroa P, et al. Platelet transfusion in cardiac surgery does not confer increased risk for adverse morbid outcomes. Ann Thorac Surg. 2008;86:543-53.

5. Karkouti K, Wijeysundera DN, Yau TM, Callum JL, Meineri M, Wasowicz M, et al. Platelet transfusions are not associated with increased morbidity and mortality in cardiac surgery. Can J Anesth. 2006;53:279-87.

6. Ferraris VA, Brown JR, Despotis GJ, Hammon JW, Reece B, Sahn JP, et al. 2011 Update to the STS and Society of Cardiovascular Anesthesiologists Blood Conservation Clinical Practice Guidelines. Ann Thorac Surg. 2011;91:944-82.

7. Henry DA, Moxey AJ, Carless PA, O'Connell D, McClleland B, Henderson KM, et al. Anti-fibrinolytic use for minimizing perioperative allogenic blood transfusion. Cochrane Database Syst Rev. 2001;CD001886.

8. Koch C, Li L, Figueroa P, Mihaljevic T, Svensson L, Blackstone EH. Transfusion and pulmonary morbidity after cardiac surgery. Ann Thorac Surg. 2009;88 1410-8.

9. Weselenbrink BD, Kleijn L, deBoer RA, Tojssen JG, Warnica WJ, Baillot R, et al. Sustained postoperative anemia is associated with an improved outcome after coronary artery bypass graft surgery: insights from the IMAGINE trial. Heart 2011;97:1590-6.

10. Lazar HL, VanderSalm T, Engelman R, Orgill D, Gordon S. Expert consensus review: prevention and management of sternal wound infections. J Thorac Cardiovascular Surg. 2016;152:962-72. 